\title{
Relationship of Admission QRS Duration and Changes in QRS Duration With Myocardial Reperfusion in Patients With Acute ST Segment Elevation Myocardial Infarction (STEMI) Treated With Fibrinolytic Therapy
}

\author{
Fehmi Kacmaz, MD; Orhan Maden, MD; Savas Aksuyek Celebi, MD*; Cagın Ureyen, MD*; \\ Ömer Alyan, MD**; Ali Rıza Erbay, MD; Hatice Selcuk, MD; Vasfi Ulusoy, MD*; \\ Yucel Balbay, MD; Erdogan Ilkay, MD
}

\begin{abstract}
Background Although ischemia induced QRS complex changes have been described previously, their relationship with impaired reperfusion, which is known to be associated with poor clinical outcomes, is not clear. Methods and Results To investigate the relationship of QRS duration changes with myocardial reperfusion, we studied 165 acute myocardial infarction (MI) patients who were administered fibrinolytic therapy for reperfusion. For each patient, 12-lead electrocardiogram (ECG) with a paper speed of $50 \mathrm{~mm} / \mathrm{s}$ was recorded on admission and repeated at the $60^{\text {th }}$ and $90^{\text {th }}$ min following fibrinolytic therapy. Based on the myocardial blush grades obtained from a control coronary angiography, patients were divided into reperfusion (grades 2,3) and impaired reperfusion (grades 0,1 ) groups. We detected impaired reperfusion in 74 patients. The patients in the impaired reperfusion group were older, more often diabetic, and had longer pain-to-needle intervals. They also had significantly longer QRS durations at admission compared to reperfusion group patients $(91 \pm 11$ vs $79 \pm 11 \mathrm{~ms}$, $\mathrm{p}<0.001)$. Reperfusion group patients showed significantly greater resolution in QRS duration at the $90^{\text {th }}$ min post fibrinolysis ECG $(18 \pm 5$ vs $5 \pm 4 \mathrm{~ms}, \mathrm{p}<0.001)$. In regression analysis, the pain-to-needle time (odds ratio (OR): $0.55,95 \%$ confidence interval (CI) $0.35-0.88, \mathrm{p}=0.012$ ), QRS duration on admission (OR: $0.80,95 \% \mathrm{CI}$ $0.67-0.97, \mathrm{p}=0.021$ ), and change in QRS duration at the post fibrinolysis $90^{\text {th }} \min$ ECG (OR: $2.43,95 \%$ CI, $1.29-4.60, \mathrm{p}=0.006$ ) were determined as independent predictors of adequate reperfusion.

Conclusion The present study, for the first time, has shown that admission QRS duration and post fibrinolysis $90^{\text {th }}$ min QRS duration changes are related to tissue reperfusion in fibrinolytic administered acute MI patients. (Circ J 2008; 72: 873-879)
\end{abstract}

Key Words: Fibrinolytic therapy; QRS duration; Reperfusion

$\mathbf{T}$ he primary goal of reperfusion therapy in acute ST segment elevation myocardial infarction (STEMI) is to achieve complete and sustained myocardial reperfusion in a timely fashion! Nevertheless, after standard current fibrinolytic regimens, many patients have suboptimal reperfusion even after successfully restored infarct related artery (IRA) patency, possibly due to loss of microvascular integrity.,3 While there is no definitely established advantage in routine immediate coronary angiography after thrombolytic administration, 4 rescue therapy might benefit a limited proportion of patients with suboptimal reperfusion, if they

(Received September 26, 2007; revised manuscript received December 28, 2007; accepted January 10, 2008)

Cardiology Department, Yuksek Ihtisas Education and Research Hospital, *Cardiology Department, Ankara Numune Education and Research Hospital, Ankara, **Cardiology Department, Faculty of Medicine, Dicle University, Diyarbakır and Cardiology Clinic, Mesa Hospital, Ankara, Turkey

Mailing address: Orhan Maden, MD, Şehit Cengiz Topel Mah.19. sok. Gulfinaz ap.121/11, Akdere/Mamak, Ankara, 06630, Turkey. E-mail: drorhanmaden@yahoo.co.uk

All rights are reserved to the Japanese Circulation Society. For permissions, please e-mail: cj@j-circ.or.jp can be identified sufficiently early 5 Impaired reperfusion after acute myocardial infarction (MI), better known as noreflow phenomenon, is associated with greater infarct size, an increased risk of death and left ventricular dysfunction? So, differentiation of a subgroup of acute MI patients who did not get benefit from fibrinolytic therapy by means of a practical, easily available and non-invasive diagnostic tool might have practical implications because this group of patients is likely to experience poorer outcomes.

Although the post fibrinolysis electrocardiogram (ECG) has shown promise as a non-invasive reperfusion marker, electrocardiographic assessment of reperfusion is traditionally based solely on changes of the ST segment. In contrast, a poor prognostic value of QRS prolongation in acute STEMI settings has been shown in previous studies. 6,7

Although in acute STEMI patients, ST segment elevation resolution for assessment of reperfusion status is in widespread use, to the best of our knowledge in fibrinolytic therapy administered patients, there are no reports evaluating the relationship of QRS duration with myocardial reperfusion. Thus, our objective in this study was primarily to investigate the relationship of admission QRS duration with myocardial reperfusion in fibrinolytic therapy administered 
acute STEMI patients. Second, we aimed to evaluate whether adequate reperfusion is associated with any change in QRS duration at $60^{\text {th }}$ and $90^{\text {th }}$ min post fibrinolysis ECGs. As the surrogate of tissue level reperfusion, we used angiographic myocardial blush grade, which was shown to be a reliable index of microvascular integrity in previous reports? ${ }^{8-11}$

\section{Methods}

From May 2005 to March 2007, 179 patients (mean age $59 \pm 10$ years, $79 \%$ male) admitted with STEMI within $12 \mathrm{~h}$ from the onset of symptoms to Ankara Yuksek Ihtisas Hospital Cardiology clinic and Ankara Numune Hospital Cardiology clinic and who were administered front loaded tissue plasminogen activator (tPA) as reperfusion therapy, were primarily enrolled in the study. STEMI was defined as typical chest pain lasting more than $30 \mathrm{~min}$ along with ST segment elevation $>1 \mathrm{~mm}$ in at least 2 consecutive electrocardiographic leads. We excluded patients older than 75 years, those with a recent history of stroke (within 3 months), those with active bleeding or bleeding diathesis, those with a recent history of trauma or major surgery (within a month), those with suspected aortic dissection, those receiving oral anticoagulant therapy with coumarin derivatives, and those with severe, uncontrolled hypertension (defined as a systolic blood pressure of more than $180 \mathrm{mmHg}$ that was unresponsive to therapy). Patients who were in shock, treated with fibrinolytic therapy in the previous $24 \mathrm{~h}$, patients with a history of coronary artery bypass grafting and patients with bundle branch blocks and patients who had severe ST segment elevation obscuring J point identification were also excluded from the study. The study was approved by each center's institutional local ethics committee and all patients gave their written informed consent.

Intravenous fibrinolytic therapy was administered as a bolus dose of $15 \mathrm{mg}$ of tPA (Actilyse, Boehringer Ingelheim, Ingelheim, Germany) followed by a 90 -min infusion in which $0.75 \mathrm{mg} / \mathrm{kg}$ of body weight was given over a period of $30 \mathrm{~min}$, followed by $0.5 \mathrm{mg} / \mathrm{kg}$ over a period of $60 \mathrm{~min}$. They also received intravenous heparin for a period of 48-72 h; the initial dose was $1,000 \mathrm{U} / \mathrm{h}$, and the dose was adjusted to obtain an activated partial-thromboplastin time between 60 and $85 \mathrm{~s}$. All patients received $300 \mathrm{mg}$ of oral aspirin and 5,000 U of IV heparin on admission. Other medications were administered according to the discretion of the treating physicians.

\section{Electrocardiographic Evaluation}

For each patient, 12 lead ECG with a paper speed of $50 \mathrm{~mm} / \mathrm{s}$ and amplification of $10 \mathrm{~mm} / \mathrm{mV}$ was recorded by using a delta 60 plus E (Remco Italia, Italy) ECG machine on admission and it was repeated at the $60^{\text {th }}$ and $90^{\text {th }}$ min following fibrinolytic therapy. ECGs were coded and all annotations were masked. QRS duration, from the onset to the $\mathrm{J}$ point, was measured manually with the help of a caliper and magnifying lens in 3 consequtive beats in the infarct-elated leads by 2 of the investigators unaware of the reperfusion status of the patient. For each of the infarct-related leads, means of 3 beats were calculated and the mean value for QRS duration in infarct-related leads was computed. The average values of QRS duration measurements obtained by the 2 investigators were used for statistical analysis. Interobserver coefficients of variation for admis- sion and postfibrinolysis at the $60^{\text {th }}$ and $90^{\text {th }}$ min ECG QRS durations were found to be 4.4, 4.8 and 5.3\%, respectively. Change in QRS duration was calculated by subtracting the post fibrinolysis QRS duration from the admission QRS duration. The summed ST segment elevation was measured by summing the ST amplitude in all leads with the ST elevation at baseline using methods described previously ${ }^{12}$

\section{Angiographic Analysis}

Cardiac catheterization was performed at a mean of 3 days after the myocardial infarct. Selective left and right coronary angiography and left ventriculography were performed in all eligible patients. Thrombolysis In Myocardial Infarction (TIMI) flow grades were assessed as previously described 13 TIMI myocardial perfusion (TMP) grade was determined on angiogram by 2 blinded experienced interventional cardiologists based on the visual assessment of contrast opacification of the myocardial territory subtended by the IRA or the vessel supplying collateral channels to the IRA, in the cases when occluded IRA was present, as previously described 10 If discordance regarding TMP grade was present, a third reader's opinion was sort. TMP grade was defined as follows: (0) no myocardial blush or contrast density; (1) minimal myocardial blush or contrast density; (2) moderate myocardial blush or contrast density but less than that obtained during angiography of a contralateral or ipsilateral non-IRA; and (3) normal myocardial blush comparable with that obtained during angiography of a contralateral or ipsilateral non-IRA. TMP grades 0 and 1 were taken as indicators of injured microvasculature and TMP grades 2 and 3 were taken as indicators of preserved microvasculature, as previously described 10

\section{Statistical Analysis}

Continuous data were presented as mean \pm SD. Differences in continuous variables between the groups were determined by the Student's t-test or the Mann-Whitney U-test for variables with or without normal distribution, respectively. To test normal distribution of continuous variables, the 1 sample Kolmogorov-Smirnov test was utilised. Categorical variables were presented as percentages and compared using the chi-square test or Fisher's exact test. The Spearman correlation coefficient was calculated to evaluate the association between 2 continuous variables. For factors found to be related to impaired reperfusion in univariate analysis, regression analyses using a backward elimination technique were performed to determine their impact independently. The odd's ratios (OR) were calculated with $95 \%$ confidence intervals (CI). For determining the predictive impact of admission QRS duration on development of impaired reperfusion, receiver operating characteristics (ROC) analyses was performed. The best cut-off value was determined and at that point, sensitivity and specificity was determined. A probability value of $\mathrm{p}<0.05$ was considered significant. Statistical analysis was performed using SPSS 11.5 (SPSS Inc, Chicago, IL, USA).

\section{Results}

Of the patients enrolled, 2 died without undergoing angiography, an additional 7 patients did not undergo cardiac catheterization for other reasons (refusal by the patient, a decision by the physician, or a clinical contraindication), and the data were incomplete for 5 patients. Therefore, the results of a total of 165 patients were taken into account for 
Table 1 Comparison of Reperfusion and Impaired Reperfusion Group Patients According to Baseline Demographic and Angiographic Parameters

\begin{tabular}{|c|c|c|c|}
\hline & $\begin{array}{c}\text { Reperfusion group } \\
(n=91)\end{array}$ & $\begin{array}{l}\text { Impaired reperfusion group } \\
\qquad(n=74)\end{array}$ & $p$ value \\
\hline Age (years) & $58 \pm 10$ & $61 \pm 9$ & 0.045 \\
\hline Male gender (\%) & $72(79)$ & $58(78)$ & 0.908 \\
\hline Systemic hypertension (\%) & $30(33)$ & $28(38)$ & 0.515 \\
\hline Diabetes mellitus (\%) & $15(17)$ & $22(30)$ & 0.042 \\
\hline Active smokers (\%) & $37(41)$ & $23(31)$ & 0.203 \\
\hline Pain-to-needle time $(h)$ & $3.3 \pm 2.1$ & $6.2 \pm 2.8$ & $<0.001$ \\
\hline Heart rate (beats/min) & $74 \pm 14$ & $79 \pm 15$ & 0.062 \\
\hline Systolic BP $(\mathrm{mmHg})$ & $128 \pm 23$ & $130 \pm 31$ & 0.582 \\
\hline \multicolumn{4}{|c|}{ Killip class on presentation (\%) } \\
\hline$I$ & $85(93)$ & $62(84)$ & \multirow{2}{*}{0.143} \\
\hline II-III & $6(7)$ & $12(16)$ & \\
\hline \multicolumn{4}{|l|}{ MI subgroup (\%) } \\
\hline Anterior wall & $47(52)$ & $50(68)$ & \multirow{2}{*}{0.039} \\
\hline Non-anterior wall & $44(48)$ & $24(32)$ & \\
\hline Prior MI history (\%) & $10(11)$ & $10(13)$ & 0.768 \\
\hline \multicolumn{4}{|l|}{ TIMI flow in IRA (\%) } \\
\hline TIMI 0/1 & $3(3)$ & $39(53)$ & \multirow{3}{*}{$<0.001$} \\
\hline TIMI 2 & $4(5)$ & $10(13)$ & \\
\hline TIMI 3 & $84(92)$ & $25(34)$ & \\
\hline \multicolumn{4}{|l|}{ Multivessel disease (\%) } \\
\hline 1 vessel & $41(45)$ & $37(50)$ & \multirow{2}{*}{0.686} \\
\hline 2-3 vessel & $50(55)$ & $37(50)$ & \\
\hline Peak $C K-M B(I U / L)$ & $257 \pm 120$ & $293 \pm 114$ & 0.050 \\
\hline
\end{tabular}

BP, blood pressure; MI, myocardial infarction; TIMI, Thrombolysis In Myocardial Infarction; IRA, infarct related artery; CK-MB, creatinine kinase MB fraction.

Table 2 Comparison of Reperfusion and Impaired Reperfusion Groups According to Electrocardiographic Parameters

\begin{tabular}{|c|c|c|c|}
\hline & $\begin{array}{l}\text { Reperfusion group } \\
(n=91)\end{array}$ & $\begin{array}{l}\text { Impaired reperfusion group } \\
\qquad(n=74)\end{array}$ & $p$ value \\
\hline Sum of ST elevations on admission ( $\mathrm{mm}$ ) & $12 \pm 7$ & $11 \pm 6$ & 0.354 \\
\hline Sum of ST depressions on admission ( $\mathrm{mm}$ ) & $3 \pm 3$ & $4 \pm 2$ & 0.060 \\
\hline QRS duration on admission ( $\mathrm{ms}$ ) & $79 \pm 11$ & $91 \pm 11$ & $<0.001$ \\
\hline QRS duration at the post fibrinolysis $60^{\text {th }} \min E C G(\mathrm{~ms})$ & $71 \pm 11$ & $89 \pm 12$ & $<0.001$ \\
\hline QRS duration at the post fibrinolysis $90^{\text {th }} \min E C G(\mathrm{~ms})$ & $61 \pm 11$ & $86 \pm 12$ & $<0.001$ \\
\hline QRS narrowing at the post fibrinolysis $60^{\text {th }} \min E C G(\mathrm{~ms})$ & $8 \pm 4$ & $2 \pm 2$ & $<0.001$ \\
\hline QRS narrowing at the post fibrinolysis $90^{\text {th }} \min E C G(\mathrm{~ms})$ & $18 \pm 5$ & $5 \pm 4$ & $<0.001$ \\
\hline
\end{tabular}

ECG, electrocardiogram.

statistical analysis. Grade 2/3 TMP was detected in 91 (55\%) patients (16 patients with grade 2 and 75 patients with grade 3 ) and these patients constituted the reperfusion group and those 74 patients having grade $1 / 2$ TMP (33 patients with grade 1 and 41 patients with grade 0 ) formed the impaired reperfusion group. A comparison of patients' baseline clinical and angiographic characteristics between reperfusion and impaired reperfusion groups are presented in Table 1.

While the 2 groups were similar in terms of gender, smoking habits and history of hypertension, we detected significant differences in terms of age, presence of diabetes mellitus (DM) and pain-to-needle time. The patients in the impaired reperfusion groups were older $(61 \pm 9$ vs $58 \pm 10$ years, $\mathrm{p}=$ $0.045)$, were more likely to be diabetic $(30 \%$ vs $17 \%, \mathrm{p}=$ $0.042)$ and had longer pain-to-needle interval $(6.2 \pm 2.8$ vs $3.3 \pm 2.1 \mathrm{~h}, \mathrm{p}<0.001)$ when compared to patients in the reperfusion group. Also, the patients in the impaired reperfusion group were more likely to have anterior MI (68\% vs 52\%, $\mathrm{p}=0.039$ ). Heart rate, blood pressure and the Killip class of patients on admission did not differ between the groups.

When angiographic parameters were taken into account, there was a significant difference between the groups regard-

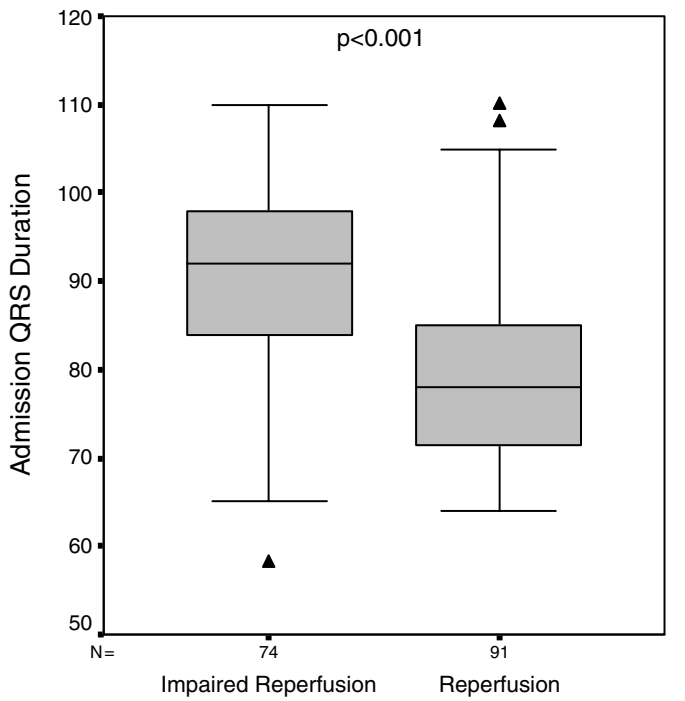

Fig 1. Distribution of admission QRS duration of patients in the impaired reperfusion and reperfusion groups. 


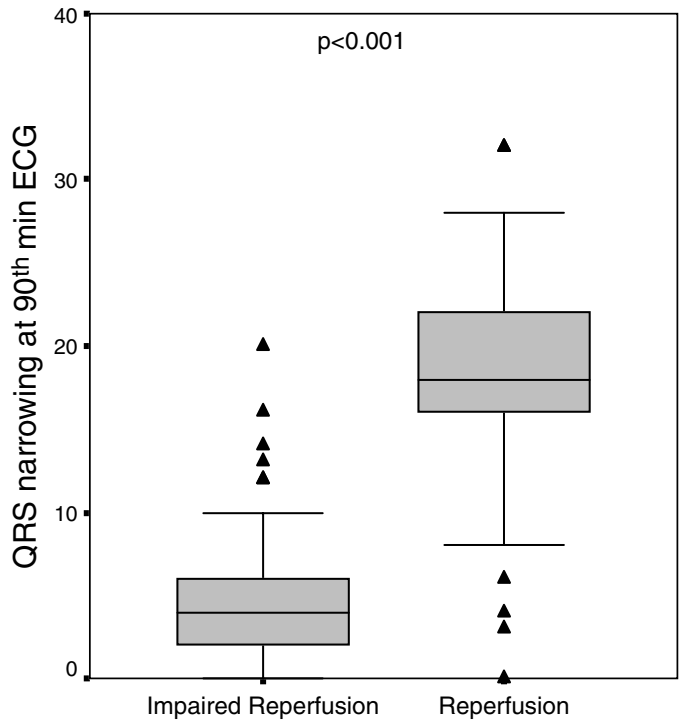

Fig 2. Distribution of the amount of change in QRS duration according to postfibrinolysis $90^{\text {th }}$ min electrocardiogram (ECG) between the groups.

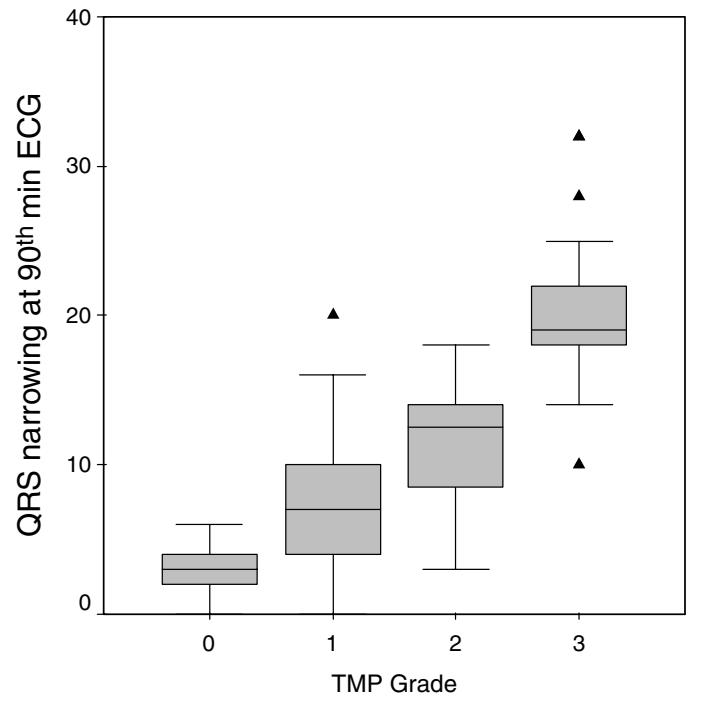

Fig 3. Distribution of QRS narrowing at the $90^{\text {th }}$ min electrocardiogram (ECG) among subgroups according to thrombolysis in myocardial infarction myocardial perfusion (TMP) grades.

Table 3 Independent Predictors of Reperfusion in Regression Analysis

\begin{tabular}{lccc}
\hline \hline & $\beta$ & OR (95\%CI) & $p$ value \\
\hline Pain-to-needle time $(h)$ & -0.594 & $0.55(0.35-0.88)$ & 0.012 \\
QRS duration on admission $(m s)$ & -0.219 & $0.80(0.67-0.97)$ & 0.021 \\
QRS narrowing at the post fibrinolysis $90^{\text {th }}$ min ECG $(\mathrm{ms})$ & 0.889 & $2.43(1.29-4.60)$ & 0.006 \\
\hline
\end{tabular}

OR, odds ratio; CI, confidence interval. Other abbreviation see in Table 2.

ing TIMI flow grade in IRA. As presented in Table 1, the TIMI flow grade 3 (complete epicardial flow) in IRA was present in $92 \%$ of patients with adequate reperfusion and in $34 \%$ of patients with impaired reperfusion $(\mathrm{p}<0.001)$.

\section{ECG Findings}

When we compared the groups in terms of electrocardiographic parameters (Table 2), although we could not detect any difference between the groups regarding total sum of ST elevations and sum of ST depressions on admission, as presented in Fig 1, there was a significant difference when QRS duration on admission was considered. Patients in the impaired reperfusion group had significantly longer QRS durations at admission compared to reperfusion group patients (91 \pm 11 vs $79 \pm 11 \mathrm{~ms}, \mathrm{p}<0.001)$. On correlation analysis, the admission QRS duration was found to correlate positively with age $(\mathrm{r}=0.180, \mathrm{p}=0.021)$ and pain-to-needle interval $(\mathrm{r}=0.500, \mathrm{p}<0.001)$. When we analysed QRS durations on post fibrinolysis ECGs from the 2 groups, QRS duration was found to be longer in the impaired reperfusion group compared to the reperfusion group, at both post fibrinolysis $60^{\text {th }}(89 \pm 12$ vs $71 \pm 11 \mathrm{~ms}, \mathrm{p}<0.001)$ and $90^{\text {th }} \mathrm{min}$ ECGs $(86 \pm 12$ vs $61 \pm 11 \mathrm{~ms}, \mathrm{p}<0.001)$.

When we took into account the amount of change in QRS duration, that is, admission QRS duration minus post fibrinolysis QRS duration, we detected a significant difference between reperfusion and impaired reperfusion groups at both post fibrinolysis $60^{\text {th }}(8 \pm 4$ vs $2 \pm 2 \mathrm{~ms}, \mathrm{p}<0.001)$ and $90^{\text {th }}$ min ECGs $(18 \pm 5$ vs $5 \pm 4 \mathrm{~ms}, \mathrm{p}<0.001)$. The mean change in QRS duration was more prominent at the $90^{\text {th }}$ min ECG compared to the $60^{\text {th }} \mathrm{min}$ post-fibrinolysis ECG $(12 \pm 8$ vs
$5 \pm 5 \mathrm{~ms}, \mathrm{p}<0.001)$. Fig 2 illustrates the comparison of the amount of change in QRS duration according to the $90^{\text {th }} \mathrm{min}$ post fibrinolysis ECG between the groups.

On correlation analysis, admission QRS duration $(\mathrm{r}=$ $-0.368, \mathrm{p}=0.001)$ and pain-to-needle time $(\mathrm{r}=-0.444, \mathrm{p}=$ 0.001 ) were found to be significantly, negatively correlated with QRS narrowing at the post fibrinolysis $90^{\text {th }} \mathrm{min}$ ECG. More importantly, we detected a strong positive correlation between QRS narrowing at the post fibrinolysis $90^{\text {th }} \mathrm{min}$ ECG and TMP grade $(r=0.873, p<0.001)$. In Fig 3, the box plot graphic illustrating the distribution of QRS narrowing at the $90^{\text {th }}$ min ECG among subgroups according to TMP grades is shown.

To understand the independent impact of individual variables that were found to be related to reperfusion in univariate analysis, we performed regression analysis including age, pain-to-needle interval, DM, anterior MI localization, QRS duration on admission, change in QRS duration at the post fibrinolysis $60^{\text {th }}$ and $90^{\text {th }}$ min ECGs and TIMI flow grade in IRA variables. After adjustment for TIMI flow grade, painto-needle time (OR: $0.5595 \% \mathrm{CI}$ 0.35-0.88, $\mathrm{p}=0.012$ ), QRS duration on admission (OR: 0.80, 95\% CI 0.67-0.97, $\mathrm{p}=0.021$ ) and change in $\mathrm{QRS}$ duration according to the post fibrinolysis $90^{\text {th }} \mathrm{min}$ ECG (OR: $2.43,95 \% \mathrm{CI}, 1.29-4.60$, $\mathrm{p}=0.006$ ) were found as independent predictors of adequate myocardial reperfusion in our study group (Table 3). While pain-to-needle time and QRS duration on admission were independent negative factors, the change in QRS duration according to the post fibrinolysis $90^{\text {th }} \mathrm{min}$ ECG was a positive factor for adequate reperfusion, as presented in Table 3.

To determine the best cut-off value for the admission 
QRS duration for predicting impaired reperfusion ROC analyses was performed; area under the ROC curve with admission QRS duration used to detect impaired reperfusion was $0.78(95 \%$ CI $0.70-0.85, \mathrm{p}<0.001)$. From that analysis, a QRS duration value of $83 \mathrm{~ms}$ was determined to be best discriminating value for impaired reperfusion. An admission QRS duration value of $83 \mathrm{~ms}$ had a sensitivity of $77 \%$ and specificity of $71 \%$ in predicting impaired reperfusion after thrombolytic treatment.

\section{Discussion}

\section{Summary of Findings}

Among the clinical variables analysed in this report, age, pain-to-needle time, having DM, anterior MI localization, and among the ECG parameters, QRS duration on admission and QRS narrowing at the post fibrinolysis $60^{\text {th }}$ and $90^{\text {th }}$ min ECGs were found to be related to adequate reperfusion in univariate analysis. In multivariate analysis, painto-needle time, QRS duration on admission and amount of QRS narrowing at the post fibrinolysis $90^{\text {th }}$ min ECG were detected as independent predictors of adequate reperfusion.

To the best of our knowledge, this study represents the first investigation in the literature showing the association of admission QRS duration with the development of reperfusion abnormalities at tissue level following fibrinolytic therapy. Furthermore, the association of the post fibrinolysis $90^{\text {th }}$ min QRS narrowing on ECG with adequate reperfusion was shown for the first time in the literature.

In this report, which is in accordance with current related literature, we have verified that a substantial number of the patients (45\%) had impaired tissue level reperfusion (TMP grade 0/1) after fibrinolytic therapy, despite an achievement of IRA patency (TIMI 2,3 flow) in 74\% of study group patients, implying that achievement of epicardial patency does not guarantee normal myocardial reperfusion. The exact cause of reperfusion abnormalities faced after acute MI is not clearly known, but it has been largely attributed to microvascular dysfunction, ${ }^{14}$ which initiates with the onset of ischemia and extends up to $48 \mathrm{~h}$ afterward. Previously, impaired myocardial reperfusion has been shown to be a major predictor of adverse outcomes in patients undergoing reperfusion therapy ${ }^{3}$ and in the literature; several modalities including myocardial contrast echocardiography, ${ }^{15}$ positron emission tomography, ${ }^{16}$ the angiographic myocardial blush grade, doppler flow wire measurements ${ }^{17}$ and the resolution of ST-segment elevation on the 12-lead ECG ${ }^{18}$ have been suggested to assess myocardial reperfusion.

In this study, as a surrogate of reperfusion, we used a myocardial blush as the TMP grade, which was previously shown to be related to enzymatic infarct size, the extent of ST segment elevation resolution, left ventricular function, long-term mortality ${ }^{8}$ and degree of myocardial salvage assessed by scintigraphy 9,11 in patients with acute MI. We used TMP grades obtained from coronary angiograms that were performed at a mean of 3 days after acute MI. Considering the time-course of reperfusion injury, which initiates after the restoration of blood flow in the IRA and lasts up to $48 \mathrm{~h}$ after acute MI onset ${ }^{14}$ it is possible to propose that the assessment of myocardial reperfusion at a later stage of acute MI (after day 1) might reflect the final steady state status more accurately!11,19

\section{Interpretation of ECG Findings}

In the present study, QRS complex changes, which prob- ably are overlooked by much more prominent ST-segment changes, in daily clinical practice were analyzed to determine if these changes that are rarely used clinically, relate to myocardial reperfusion after fibrinolytic treatment, in the setting of acute STEMI.

In agreement with our findings, QRS prolongation, which is associated with ischemia, was reported in experimental models as well as in human studies $2^{20,21}$ In a recent study by Weston et $\mathrm{al}^{20}$ conducted on dogs undergoing experimental coronary occlusion, QRS prolongation following coronary occlusion and its adverse implications on myocardial salvage had been reported. Similiarly, Cantor et al ${ }^{21}$ reported QRS prolongation in majority of their study group patients undergoing percutaneous transluminal coronary angioplasty and they reported greater prolongation in QRS duration when proximal and middle segments of major arteries were occluded. Similarly transient QRS prolongation during typical anginal pain in patients having documented coronary artery disease was shown by Michaelides et $\mathrm{al}^{22}$ using signal-averaged ECG.

In contrast, a wider QRS duration might be a reflection of more extensive damage to the myocardium and a greater amount of infarction. ${ }^{23}$ A moderate positive correlation was detected between admission QRS duration and pain-toneedle interval, which is in support of this association. Accordingly, in post MI patients, the association of QRS prolongation with adverse cardiovascular events has been reported $6,7,23$

During coronary occlusion, the most likely underlying physiologic mechanism of QRS prolongation is the slowing of conduction within areas of ischemia ${ }^{20}$ In experimental models of myocardial ischemia, demonstration of the association of QRS prolongation with Purkinje-ventricular conduction delay is further support for this mechanism? ${ }^{2-26}$ Consistently, the correlation we detected between admission QRS duration and ischemia duration in our study group is in favour of the idea of ischemia as a mechanism of QRS prolongation. QRS prolongation might be a sign of extensive ischemia and a poor metabolic state, which was shown to worsen with the delay in reperfusion6,27 Late reperfusion was previously found to be associated with impaired reperfusion, larger infarct size and higher mortality, even after achievement of TIMI 3 flow? 7

In patients with STEMI, QRS prolongation was considered to be a mainly dynamic phenomenon induced by ischemia and likely to be relieved by successful reperfusion? Our finding of more significant narrowing in QRS duration in the reperfusion group is in support of this dynamic nature of change in QRS duration showing resolution after successful reperfusion. The correlation we observed between QRS narrowing and pain-to-needle time is another factor of support for this dynamic nature of QRS changes. We proposed that in patients with a longer ischemic period, irreversible microvascular damage had occurred and such patients had longer QRS durations at admission, and less or no change in QRS duration was observed in these patients reflecting impaired reperfusion. To attain adequate myocardial reperfusion, in addition to a patent IRA, anatomically and functionally preserved microvasculature is needed. Similar QRS duration changes in a primary angioplasty setting was reported by Tsukahara et $\mathrm{al}^{6}$ who noted normalization of QRS duration within 24h of successful angioplasty in 79\% of patients having intermediately prolonged QRS duration at admission. Reversal of ischemia induced electrocardiographic changes are regarded as a functional index of the 
electrical activity of the jeopardized myocardium, and electrocardiographic indices of reperfusion was suggested to be a better representation of microvasculature status? 28

\section{Conclusion}

Identification of acute STEMI patients who are expected to be at a higher risk of impaired reperfusion after fibrinolytic therapy by means of an easy, simple, bed-side applicable diagnostic modality might provide help in the discrimination of a higher risk patient subgroup and also identify those subjects who benefit most from rescue interventions. In this study, we have shown the association of admission QRS duration with impaired reperfusion. Based on our findings, acute STEMI patients having QRS duration values above $83 \mathrm{~ms}$ should be considered to be at a higher risk of impaired reperfusion after lytic therapy. Perhaps for these patients, as initial revascularisation modality, primary percutaneous interventions, which was shown to be a more direct, rapid and effective means of attaining IRA patency, should be considered. Taking into account our finding of a post fibrinolysis greater resolution in QRS duration in the adequate reperfusion group compared to the impaired reperfusion group, it is possible to suggest that these QRS duration changes are reflections of a dynamic nature of the ischemia and reperfusion process in acute MI settings. In acute STEMI settings, it should be investigated further whether algorithms, combining QRS duration changes with ST segment changes for assessment of the myocardial reperfusion, might be more helpful in early risk stratification and provide a better discrimination of patients who require rescue intervention.

\section{Study Limitations}

This was a small-sized study and there was not a clear standardised method for the measurement of QRS duration, which has normal range of $60-80 \mathrm{~ms}$. In the presence of abnormalities of both waveforms, it is often difficult to precisely determine the junction between the end of the QRS complex and the beginning of the ST segment. Second, in this study, we used TMP grade as a surrogate of tissue reperfusion. Using another modality to define reperfusion could change the distribution of patients among the reperfusion or impaired reperfusion groups. In addition, this study included patients reperfused by fibrinolytic treatment. It must be investigated whether our findings can be extrapolated to an angioplasty group. One drawback of the current study comes from the manual measurement of QRS duration. The use of automated or computerized ECG measurement techniques might help in the standardisation of QRS duration measurements in future studies.

\section{Acknowledgment}

Part of this study data was presented as an oral abstract at the $34^{\text {th }}$ International Congress on Electrocardiology in Istanbul, 27-30 June 2007.

\section{References}

1. Braunwald E. The open-artery theory is alive and well--again. $N$ Engl J Med 1993; 329: 1650-1652.

2. Ito H, Tomooka T, Sakai N, Yu H, Higashino Y, Fujii K, et al. Lack of myocardial perfusion immediately after successful thrombolysis: A predictor of poor recovery of left ventricular function in anterior myocardial infarction. Circulation 1992; 85: 1699-1705.

3. Ito H, Maruyama A, Iwakura K, Takiuchi S, Masuyama T, Hori M, et al. Clinical implications of the 'no-reflow' phenomenon: A predic- tor of complications and left ventricular remodeling in perfused anterior wall myocardial infarction. Circulation 1996; 93: 223-228.

4. Michels KB, Yusuf S. Does PTCA in acute myocardial infarction affect mortality and reinfarction rates?: A quantitative overview (meta-analysis) of the randomized clinical trials. Circulation 1995; 91: 476-485.

5. Mounsey JP, Skinner JS, Hawkins T, MacDermott AF, Furniss SS, Adams PC, et al. Rescue thrombolysis: Alteplase as adjuvant treatment after streptokinase in acute myocardial infarction. Br Heart $J$ 1995; 74: 348-353.

6. Tsukahara K, Kimura K, Kosuge M, Shimizu T, Sugano T, Hibi K, et al. Clinical implications of intermediate QRS prolongation in the absence of bundle-branch block in patients with ST-segment-elevation acute myocardial infarction. Circ J 2005; 69: 29-34.

7. Go AS, Barron HV, Rundle AC, Ornato JP, Avins AL. Bundlebranch block and in-hospital mortality in acute myocardial infarction: National Registry of Myocardial Infarction 2 Investigators. Ann Intern Med 1998; 129: 690-697.

8. van't Hof AW, Liem A, Suryapranata H, Hoorntje JC, de Boer MJ, Zijlstra F. Angiographic assessment of myocardial reperfusion in patients treated with primary angioplasty for acute myocardial infarction: Myocardial blush grade: Zwolle Myocardial Infarction Study Group. Circulation 1998; 97: 2302-2306.

9. Angeja BG, Gunda M, Murphy SA, Sobel BE, Rundle AC, Syed M, et al. TIMI myocardial perfusion grade and ST segment resolution: Association with infarct size as assessed by single photon emission computed tomography imaging. Circulation 2002; 105: 282-285.

10. Gibson CM, Cannon CP, Murphy SA, Ryan KA, Mesley R, Marble SJ, et al. Relationship of TIMI myocardial perfusion grade to mortality after administration of thrombolytic drugs. Circulation 2000; 101: $125-130$.

11. Dibra A, Mehilli J, Dirschinger J, Pache J, Neverve J, Schwaiger M, et al. Thrombolysis in myocardial infarction myocardial perfusion grade in angiography correlates with myocardial salvage in patients with acute myocardial infarction treated with stenting or thrombolysis. J Am Coll Cardiol 2003; 41: 925-929.

12. Schroder R, Wegscheider K, Schroder K, Dissmann R, MeyerSabellek W. Extent of early ST segment elevation resolution: A strong predictor of outcome in patients with acute myocardial infarction and a sensitive measure to compare thrombolytic regimens: A substudy of the International Joint Efficacy Comparison of Thrombolytics (INJECT) trial. J Am Coll Cardiol 1995; 26: 1657-1664.

13. The TIMI Study Group. The Thrombolysis in Myocardial Infarction (TIMI) Trial. N Engl J Med 1985; 31: 932-936.

14. Mukherjee D, Moliterno DJ. Achieving tissue-level perfusion in the setting of acute myocardial infarction. Am J Cardiol 2000; 85: 39C$46 \mathrm{C}$.

15. Greaves K, Dixon SR, Fejka M, O'Neill WW, Redwood SR, Marber MS, et al. Myocardial contrast echocardiography is superior to other known modalities for assessing myocardial reperfusion after acute myocardial infarction. Heart 2003; 89: 139-144.

16. Muzik O, Beanlands RS, Hutchins GD, Mangner TJ, Nguyen N, Schwaiger M. Validation of nitrogen-13-ammonia tracer kinetic model for quantification of myocardial blood flow using PET. J Nucl Med 1993; 34: 83-91.

17. Tsunoda T, Nakamura M, Wakatsuki T, Nishida T, Asahara T, Anzai $\mathrm{H}$, et al. The pattern of alteration in flow velocity in the recanalized artery is related to left ventricular recovery in patients with acute infarction and successful direct balloon angioplasty. J Am Coll Cardiol 1998; 32: 338-344.

18. Clemmensen P, Ohman M, Sevilla D, Peck S, Wagner NB, Quigley PS, et al. Changes in standard electrocardiographic ST segment elevation predictive of successful reperfusion in AMI. Am J Cardiol 1990; 66: $1407-1411$

19. Ito H, Iwakura $\mathrm{K}, \mathrm{Oh} \mathrm{H}$, Masuyama T, Hori M, Higashino Y, et al. Temporal changes in myocardial perfusion patterns in patients with reperfused anterior wall myocardial infarction: Their relation to myocardial viability. Circulation 1995; 91: 656-662.

20. Weston P, Johanson P, Schwartz LM, Maynard C, Jennings RB, Wagner GS. The value of both ST-segment and QRS complex changes during acute coronary occlusion for prediction of reperfusion-induced myocardial salvage in a canine model. J Electrocardiol 2007; 40: $18-25$.

21. Cantor AA, Goldfarb B, Ilia R. QRS prolongation: A sensitive marker of ischemia during percutaneous transluminal coronary angioplasty. Catheter Cardiovasc Interventions 2000; 50: 177-183.

22. Michaelides AP, Dilaveris PE, Psomadaki ZD, Richter DJ, Andrikopoulos GK, Pitsilides N, et al. QRS prolongation on the signal-averaged electrocardiogram versus ST-segment changes on the 12-lead electrocardiogram: Which is the most sensitive electrocar- 
diographic marker of myocardial ischemia? Clin Cardiol 1999; 22: $403-408$.

23. Wong CK, Gao W, Stewart RA, van Pelt N, French JK, Aylward PE, et al. Risk stratification of patients with acute anterior myocardial infarction and right bundle-branch block: Importance of QRS duration and early ST-segment resolution after fibrinolytic therapy. Circulation 2006; 114: 783-789.

24. Mendez C, Mueller WJ, Meredith J, Moe GK. Interaction of transmembrane potentials in canin purkinje fibers and at purkinjefibermuscle junctions. Circ Res 1969; 24: 361-372.

25. Hamilin RL, Pipers FS, Hellerstein HK, Smith CR. QRS alteration immediately following production of left ventricular free wall ischemia in dogs. Am J Physiol 1968; 215: $1032-1040$.
26. Grant RP, Dodge HT. Mechanisms of QRS complex prolongation in man: Left ventricular conduction disturbances. Am J Med 1956; 20: 834-852.

27. De Luca G, van't Hof AW, de Boer MJ, Ottervanger JP, Hoorntje JC, Gosselink AT, et al. Time-to-treatment significantly affects the extent of ST-segment resolution and myocardial blush in patients with acute myocardial infarction treated by primary angioplasty. Eur Heart J 2004; 25: 1009-1013.

28. Bellandi F, Leoncini M, Maioli M, Toso A, Gallopin M, Piero Dabizzi R. Markers of myocardial reperfusion as predictors of left ventricular function recovery in acute myocardial infarction treated with primary angioplasty. Clin Cardiol 2004; 27: 683-688. 